ISSN electrónico: 2172-9077

DOI: http://dx.doi.org/10.14201/fjc201613207211

\title{
DROGAS: DE LA REALIDAD A LA FICCIÓN AUDIOVISUAL
}

\author{
Dra. Rebeca MARTÍN NIETO \\ Profesora Visitante. Universidad Rey Juan Carlos, España \\ E-Mail: rebeca.martin@urjc.es
}

Fecha de recepción de la reseña: 11/11/2016

Fecha de aceptación definitiva: 12/11/2016

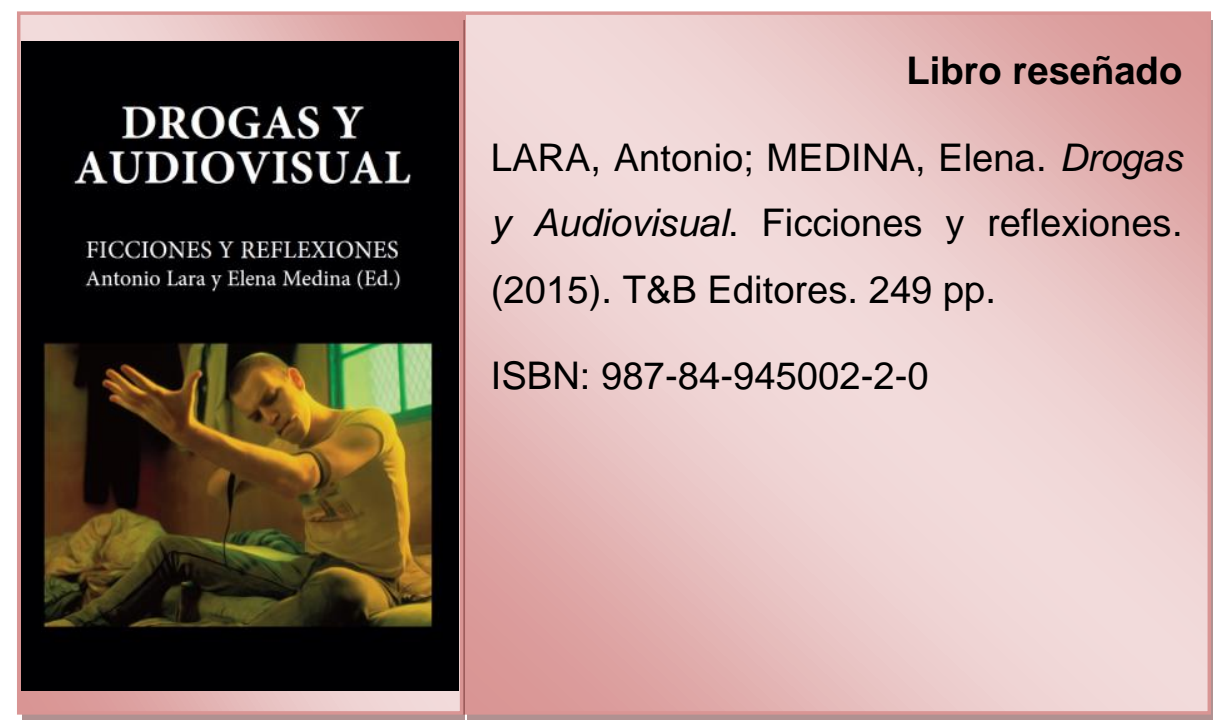

La función social que el audiovisual ha tenido durante décadas en el medio cinematográfico y televisivo está fuera de duda. La representación dramática de la realidad recogida en los medios audiovisuales supone un potente agente socializador que puede llegar a influir y constituir conductas sociales. De ahí deriva la necesidad de concienciación y sentido de la responsabilidad de los creadores audiovisuales en el planteamiento de sus obras. Si bien, algunos autores como Jarvie (1970 en Pardo, 1998), consideran la imposibilidad de establecer una relación directa entre la cinematografía y los efectos sociales - por la cantidad de factores implicados en los mismos-, no puede minusvalorarse su repercusión social. Drogas y audiovisual. Ficciones y Reflexiones supone un espacio de reflexión en torno al tratamiento, representación, contenidos y producción técnica de la drogadicción en el audiovisual. 
La publicación surge de una estrecha interacción entre la Universidad (Universidad Rey Juan Carlos) y la Fundación de Ayuda contra la Drogadicción (FAD) ${ }^{1}$, donde la Universidad aporta su saber sobre el audiovisual y la fundación su gran conocimiento y experiencia en torno a las drogas. En sus inicios la relación se ceñía a la producción de audiovisuales libres con fines didácticos para la fundación. Posteriormente esa relación se extendió durante varios años y varios proyectos de investigación. La parte práctica estaba cubierta, pero no así la teórica. La escasez de fuentes documentales y científicas respecto a la relación de la drogadicción y el audiovisual llevaron a los autores a proponer la obra que ahora se reseña.

Encontrar lugares comunes entre las dos instituciones no fue un camino sencillo por la diferencia de opiniones y puntos de vista respecto a las drogas que tenían los agentes de ambas partes: más abierta y flexible en la universidad, más preventiva y de rechazo a su consumo en la fundación; tal y como exponen los autores en la introducción del libro. Cuando se trata el consumo de drogas desde el audiovisual, entran en conflicto dos visiones: la socialización -como acercamiento cultural necesario para interpretar el mundo- y la legitimación -se usa el cine para justificar o legitimar creencias, actos e ideas sociales (Pardo, 1998).

Estos dos ámbitos de tratamiento del contenido audiovisual podrían identificarse con las dos grandes partes en las que se divide el texto. La primera, que en la obra recibe el título de Experiencias y reflexiones, recoge los cinco primeros capítulos, los más sociológicos, donde se relacionan el audiovisual con la educación, la creación, el retrato social o la prevención. Mientras que la segunda, Drogas en la ficción, es la que se correspondería con el espacio de legitimación y la que recopila algunos ejemplos de análisis audiovisual desde el punto de vista del tratamiento del contenido o desde el más técnico de la realización. Es la variedad de perspectivas y la heterogeneidad de enfoques lo que da, precisamente, riqueza a la obra.

\section{EXPERIENCIAS Y REFLEXIONES}

El volumen comienza con un repaso de las posibilidades que ofrecen los recursos audiovisuales en el ámbito de la educación. Exponen Rodríguez, Ares y Prat, en el primer capítulo, la extensión que se ha producido en los últimos años del uso de los medios de comunicación entre adolescentes y jóvenes y cómo aquellos pueden facilitar su aprendizaje y asimilación de conductas. Al mismo tiempo que reconocen y valoran el esfuerzo personal, la capacidad de decisión, el aprendizaje experiencial y el aprendizaje significativo.

Francisco Mora en Neuroeducación (2013), concreta tres habilidades sociales básicas «la primera es la imitación; la segunda, la atención compartida, y la tercera, la comprensión empática [...] capacidad emocional innata; de hecho, es quizá el mecanismo social de aprendizaje más poderoso». Los autores destacan el trabajo cooperativo y el impacto emocional que engloban buena parte de estas tres habilidades básicas a la hora de conseguir un cambio de actitudes hacia las drogas y entienden que los medios audiovisuales pueden facilitar el acercamiento a este tema. Aunque reconocen también que el recurso audiovisual por sí solo no alcanzará todos los objetivos de concienciación y prevención que se plantea la FAD. Se hacen necesarias intervenciones en los espacios de ocio y en la acción formativa para alcanzarlo.

\footnotetext{
${ }^{1}$ Específicamente del proyecto de investigación «Estudio de la ficción como herramienta educativa para fomentar la responsabilidad ante el consumo de drogas» desarrollado por ambas instituciones y que nace en el año 2009.
} 
A continuación, Lara Martínez y Medina de la Viña muestran un retrato claro de lo que en educación se conoce ya como aprendizaje-servicio ${ }^{2}$, método que busca unir el éxito educativo (adquisición de conocimientos, habilidades y valores) con el compromiso social: los alumnos aprenden a ser competentes en su área al mismo tiempo que son útiles a la comunidad. Los editores realizan una exposición detallada de los proyectos de investigación que han conformado el marco teórico en el que situar la experiencia con FAD y el proceso de producción de los recursos audiovisuales que servirán después a la fundación para hacer concienciación y prevención social respecto a la drogadicción.

Siguiendo en la línea de la socialización, Fernández Manzano y Linares Palomar muestran el cine como agente socializador, reflector de comportamientos sociales en Los huelepega: drogas, menores y abandono. El documental cinematográfico Quemando el Estrecho muestra sin tapujos la inmigración ilegal y las dificultades de los menores inmigrantes en el Estrecho. En este compendio se explica su proceso de producción, a la vez que se muestra cómo, de manera audiovisual, estos testimonios pueden ayudar también a la sensibilización y comprensión del fenómeno de la inmigración, no solo entre los jóvenes, sino también entre los agentes implicados en el proceso de atención a los menores inmigrantes (voluntarios, $\mathrm{ONG}$, etc.).

La aportación de López Vidales y Gómez Rubio se centra en el análisis de Jóvenes y drogas: un análisis de lo más visto en YouTube. Profundizan en «el conocimiento de cómo percibe el público joven» las campañas de concienciación contra la drogadicción a través del canal de intercambio de material audiovisual por excelencia, YouTube; y lo hacen a través de un análisis exhaustivo del código audiovisual, del auditivo, del visual, de los personajes y del propio mensaje. Y encuentran que la repercusión de los vídeos sobre prevención de la drogadicción no tiene una gran aceptación en número de reproducciones: el que más, alrededor de 280.000 visualizaciones en dos años, cuando es sencillo que vídeos con impacto alcancen el millón de visitas en pocos días. Concluyen que la línea de producción de estos vídeos continúa la línea de producción y temática de años anteriores y que era difundida a través de otros medios. Cambian el canal, pero no el mensaje.

Este bloque «socializadon» se completa con Estados de conciencia y creatividad que bien podría haber sido incluido como prólogo del libro. Se trata del capítulo más intenso y reflexivo de toda la obra. Aurelio del Portillo nos adentra en la consideración de que la consciencia y la creatividad van íntimamente unidas, al contrario de lo que puede parecer cuando se favorece la inconsciencia para la creación artística. La falta de vivencia, de plenitud, de experiencia consciente, de plena atención, de contemplación, de equilibrio interior frente al ruido mediático, el estrés, la tensión o la preocupación serían las claves para alcanzar, según Portillo, no solo el éxtasis alejado de artificios sino, también, la felicidad. Las drogas serían «trampantojos» para salvar las apariencias de realidades personales y sociales incómodas. «Saber alternar la inteligencia lógica con la inteligencia creativa es el secreto del éxito [...] Esta alternancia entre una y otra forma de pensar ha sido la clave de todos los talentos y genios» (Sánchez, 2010 en Lara y Medina, 2015). Prima el autor la potencia de otras inteligencias para alcanzar «la intuición, la inspiración, la imaginación y la fantasía», antes que recurrir a sustancias o experiencias que provocan estados alterados de la conciencia y antes que la inmersión en la enorme saturación de estímulos externos que adormecen la reflexión e imaginación.

\footnotetext{
${ }^{2}$ Zerbikas Fundacioa: Aprendizaje y Servicio Solidario es una propuesta educativa que combina aprendizaje y servicio a la comunidad en un mismo proyecto. En él, los participantes motivados hacia determinada problemática actúan sobre el entorno con intención de mejorarlo. La interacción entre aprendizaje y servicio intensifica los efectos de ambos. El aprendizaje mejora el servicio a la comunidad, que gana en calidad de vida y en equidad. El servicio da sentido al aprendizaje, al permitir que se transfiera a la realidad en forma de acción.
} 


\section{TRATAMIENTO AUDIOVISUAL DE LAS DROGAS EN LA FICCIÓN}

Esta parte de la compilación es la que está dedicada al análisis de casos concretos, a indagar en el tratamiento, contenido y producción técnica de diversas obras de ficción cinematográfica y televisiva que han tratado la drogadicción a lo largo del tiempo.

Son ejemplos de «dramas de reafirmación» de las propias creencias, actitudes y valores (Jowett y Linton, en Pardo 1998) en relación a esa misión de «legitimación» que plantean los investigadores de la función social del audiovisual. Federico Dávalos (2010 en Arias Flores) lo resume como aquellas obras que contribuyen «en el ámbito cotidiano, al registro de la familia, las pandillas, los delincuentes; permite la recopilación y extracción de información; cumple con la función de enseñar y coadyuva a la investigación sobre múltiples temas».

El análisis de obras internacionales tiene su representación en el primer y último capítulo de esta parte con Trainspotting y Breaking Bad, cine y televisión. Gutiérrez San Miguel y Álvaro Manzano, autores respectivos, las tratan desde diferentes puntos de vista. En el primero se analiza la obra desde una perspectiva más global. Expone la ficha técnico artística y se para a analizar su estructura narrativa, el espacio y el contexto, para terminar ofreciendo una reflexión sobre las adicciones representadas. La serie estadounidense por su parte está tratada desde un punto de vista más concreto, el de la fotografía y el uso del color para condicionar, no solo espacios y ambientes, sino también, y sobre todo, personajes y su relación con las drogas; al mismo tiempo que influye en la manera en que el espectador percibe la obra. La luz se usa también para indicar al receptor dónde y cómo debe mirar. Este proceso se desarrolla desde el rodaje hasta el montaje, y donde el etalonaje cobra un papel protagonista y fundamental. De esta manera "la ficción no solo supera la realidad, sino que en algún caso la condiciona y la altera".

Mapa histórico de la droga en el cine español del tercer milenio hace un repaso por las obras cinematográficas en España durante la primera década del siglo XXI. Parte de la premisa de que existe en la representación audiovisual un patrón común: consumo de drogas blandas, cocaína y finalmente heroína y degradación. La evolución de la representación de las drogas en España varía desde la permisividad y relajamiento de los años ochenta, hasta la actualidad, más cercana a la concienciación y prevención de su consumo. Elige ocho películas entre el 2000 y el 2008, expone cada uno de sus argumentos y concluye que el factor común a todas ellas es que «droga es sinónimo de muerte».

Entre los capítulos que eligen la ficción española para profundizar en la representación de las drogas están El pico, una película sobre la realidad de la heroína en España en los años ochenta, de José M. ${ }^{a} \mathrm{Me}-$ rino Blázquez. Lo más interesante de este capítulo es la manera en que el autor va relacionando aspectos reflejados en la ficción con la realidad de los años de la Movida. Aparecen temas como la adicción prenatal y sus consecuencias en los ya nacidos, el terrorismo, el abandono escolar, la «espiral de la droga» (de los porros a la heroína), incomprensión o negación familiar del consumo, aumento de la violencia y la criminalidad, infecciones por VIH o consecuencias de salud, sociales y psicológicas del consumo y muerte. Es una película dura sobre la drogadicción y más cruda aún cuando se abren los ojos a la realidad que representa de forma tan clara en la recopilación que reseñamos.

En el capítulo dedicado a Cuéntame cómo pasó, Julio Moreno Díaz hace un repaso sociológico de los años de la Movida a través de la evolución de la serie para centrarse en aquellas temporadas en las que las drogas fueron protagonistas de la trama. El momento en el que Inés, hija mayor de los Alcántara, entra en ese mundo y la batalla de su familia para lograr que salga del círculo vital en el que ha caído: búsqueda de la evasión personal, sensación de libertad, refugio en la drogadicción, intentos de salir, recaídas, ayuda familiar y más recaídas e intentos de recuperación, hasta la completa desintoxicación. En el repaso de Moreno Díaz aparecen elementos de la ficción que ayudan a contextualizar la época: 
el papel de la familia, la imagen estereotipada de la mujer, el hogar como espacio representado de convivencia y núcleo de la transformación familiar, consecuencias sociales de la extensión de las drogas, la recuperación unida a la voluntad propia de los afectados y la falta de información y tratamiento de los drogadictos, etc. y hacen de esta ficción (y de su explicación escrita en este libro) un espacio de reconocimiento de la realidad por su fidelidad con la realidad de la época.

Hasta el momento se han tratado cualidades de representación social o individual desde un punto de vista externo. En el capítulo Aproximación al tratamiento cinematográfico de los estados de embriaguez por el uso de diversas drogas se ofrece un panorama diferente: la vivencia subjetiva del personaje consumidor de drogas y lo hace a través del examen de ficciones como Crank, Réquiem por un sueño o Destino: Woodstock. entre otras. María Lara describe las secuencias que recrean de manera subjetiva las impresiones y sensaciones que experimentan quienes consumen drogas trasladando al espectador a su mundo interior. $\mathrm{Y}$ concluye que, junto a la música, hay determinados efectos visuales que ayudan a recrearlo: etalonaje, distorsión, desenfoques, variación en la sensación del tiempo con aceleraciones o ralentizaciones, etc.

El tratamiento que el audiovisual hace de la drogadicción, tal y como se desarrolla y explicita en Drogas y audiovisual: ficciones y reflexiones, favorece el acercamiento al tema de manera teórica; no solo por el texto en sí, sino también por la extensa recopilación de fuentes documentales de todo tipo que se añaden al final del texto. La selección y transversalidad de perspectivas ofrecidas por los editores y autores ayudan al lector a formar una idea general de cómo la ficción audiovisual muestra el mundo de las drogas y las personas afectadas por ellas y es precisamente este cariz multifocal lo que otorga a esta obra mayor valor; al mismo tiempo que sirve de fuente real para entender el mundo de las drogas y sus consecuencias personales y sociales.

\section{FUENTES DOCUMENTALES}

Arias Flores, L. D. (2010). El cine y su función social. Gaceta. Recuperado de: http://gacetapoliticas.blogspot.com.es/2010/03/el-cine-y-su-funcion-social.html

Mora, F. (2013). Neuroeducación. Alianza Editorial.

Pardo, A. (1998). Cinema and Society in David Puttnam. Communication \& Society, 11(2), 53-90.

Zerbikas Fundacioa. (s.f.). Definición. Aprendizaje y servicio solidario. Recuperado de: http://www.zerbikas.es/que-es-ayss/definicion/ 